\title{
Histochemical study of lectin-binding patterns in the rat vomeronasal organ during postnatal development
}

\author{
Wonho Lee ${ }^{1, \uparrow}$, Meejung Ahn ${ }^{2, \uparrow}$, Changnam Park ${ }^{1, \uparrow}$, Kazumi Taniguchi, \\ Changjong Moon ${ }^{4}$, Taekyun Shin ${ }^{1, *}$ \\ ${ }^{1}$ Department of Veterinary Anatomy, College of Veterinary Medicine and Veterinary Medical Research Institute, \\ Jeju National University, Jeju 690-756, Korea \\ ${ }^{2}$ Department of Anatomy, School of Medicine, Jeju National University, Jeju 690-756, Korea \\ ${ }^{3}$ Laboratory of Veterinary Anatomy, School of Veterinary Medicine, Kitasato University, \\ Towada, Aomori 034-8628, Japan \\ ${ }^{4}$ Department of Veterinary Anatomy, College of Veterinary Medicine, Chonnam National University, \\ Gwangiu 500-757, Korea
}

(Received: January 4, 2012; Revised: March 3, 2012; Accepted: March 5, 2012)

\begin{abstract}
Histochemical patterns of lectin binding during development of the rat vomeronasal organ (VNO) were studied to determine whether glycoconjugates are differently expressed after birth. Three types of lectins, Dolichos biflorus agglutinin (DBA), wheat germ agglutinin (WGA), and Ulex europaeus agglutinin I (UEA-I), were studied histochemically in the rat VNO at various stages post-birth: postnatal days 1 and 7, the preweaning period (4 weeks after birth), and at sexual maturity (8 weeks after birth). The free border of the vomeronasal sensory epithelium was positive for both WGA and UEA-I in rats of all ages; whereas, VNO receptor cells and supporting cells were positive only for both WGA and UEA-I from 4 weeks after birth. DBA reactivity was detected in the free border but less so in receptor cells and supporting cells. WGA and UEA-I, but not DBA, showed similar patterns in various ages. In the Jacobson's gland, WGA, UEA-I and DBA were detected in some acini from 4 weeks after birth but not at postnatal days 1 or 7. Collectively, reactivity for three lectins, WGA, UEA-I and DBA, increased in receptor cells and gland acini during postnatal development, possibly contributing to the enhanced chemoreception in rats.
\end{abstract}

Keywords : lectin histochemistry, postnatal development, rat, vomeronasal organ

\section{Introduction}

The vomeronasal organ (VNO) has been thought to be a specialized sense organ for the perception of pheromone. Pheromones are associated with reproductive behavior and chemosensory reception in animals [2-4, 24]. As a specialized sense organ, VNO has a tubular structure, and its lumen is surrounded by two types of epithelia [22]. The medial wall of the lumen is lined with the vomeronasal sensory epithelium; whereas, the lateral wall of the VNO is covered with the vomeronasal nonsensory epithelium [7, 22]. The axons of vomeronasal sensory receptor neurons terminate in the glomeruli of the accessory olfactory bulb [8]. In rats, it has been observed that the olfactory epithelium completes development before birth, while the sensory epithelium of VNO develops after birth in rats [15]. During postnatal VNO development, neurosensory epithelia have been shown to display increased carbohydrate binding and thus to be functionally active in pigs $[6,16,23]$.

The carbohydrate (lectin-binding) moieties of glycoproteins and glycolipids are important for a variety of biological processes, including cellular adhesion, cellular recognition, protein folding, and signal transduction [5, 9, 25]. All lectin molecules possess two or more carbohydrate-binding sites, which are essential for the agglutination of cells and reactivity with complex carbohydrates [5]. Each lectin binds to a specific sugar

\footnotetext{
*Corresponding author

Tel: +82-64-754-3363, Fax: +82-64-756-3354

E-mail: shint@jejunu.ac.kr

${ }^{\dagger}$ The first three authors contributed equally to this work.
} 
or group of sugars. Many studies have focused on lectinbinding patterns in the $\mathrm{VNO}$ in domestic animals including sheep and pigs [16, 19], horses [10], and laboratory animals including mice [20], rats [12, 17, 18, 21] and marmosets [14]. The results of these studies suggest that the distribution of carbohydrates on the surfaces of the vomeronasal neuroepithelial cells is species and/or cell-type specific. Although some lectins have been studied in the neurosensory epithelia of the rat VNO [12, 17, 18], little is known about developmental changes in lectins such as wheat germ agglutinin (WGA), Ulex europaeus agglutinin I (UEA-I), and Dolichos biflorus agglutinin (DBA) in the rat VNO, including cell-specific reactivity in the vomeronasal neuroepithelium and gland acini.

The aim of this study was to investigate three lectins, WGA, UEA-I and DBA, in the VNO of postnatal, preweaning and sexually matured rats.

\section{Materials and Methods}

\section{Animals}

Sprague-Dawley rats $(200 \sim 250 \mathrm{~g})$ were purchased from Daehan Biolink (Korea) and mated in our laboratory facility. All experimental procedures were conducted in accordance with the Guidelines for the Care and Use of Laboratory Animals of Jeju National University, Korea.

\section{Tissue preparation}

Under deep ether anesthesia, three rats from each group were killed under deep anesthesia. VNO tissues were excised at $1(n=3)$ and $7(n=3)$ days after birth, 4 weeks after birth (preweaning period $(n=3)$ ), and 8 weeks after birth (sexual maturity $(n=3)$ ).

\section{Histological analysis}

After animals had been euthanized, the VNO tissues were immediately removed from the nasal cavities and fixed in $10 \%$ buffered formalin for $48 \mathrm{~h}$. The formalinfixed tissues were trimmed and decalcified using a decalcifying solution (sodium citrate-formic acid) [13], which was changed several times, until the bony tissue had softened. Next, the tissues were dehydrated in a graded ethanol series $(70 \%, 80 \%, 90 \%, 95 \%$ and $100 \%)$, cleared in xylene, embedded in paraffin, and sectioned to a thickness of $5 \mu \mathrm{m}$. After deparaffinization, the sections were stained with hematoxylin and eosin using routine histological techniques.

\section{Lectins used in this study}

The following lectins (all of which were purchased from Sigma Chemical, USA) were used: Triticum vulgaris (wheat germ) agglutinin (WGA), Ulex europaeus agglutinin I (UEA-I), and Dolichos biflorus agglutinin (DBA). All of the lectins came peroxidase-labeled. The specificities of the lectins are described in our previous paper [16].

\section{Lectin histochemistry}

The VNO samples were dehydrated through immersion in a graded ethanol series $(70 \%, 80 \%, 90 \%, 95 \%$ and $100 \%$ ), cleared in xylene, embedded in paraffin, and sectioned to a thickness of $5 \mu \mathrm{m}$ using a microtome. The sections were mounted on glass microscope slides, and the paraffin was removed. The sections were then rehydrated. Endogenous peroxidase activity was blocked through incubation for $30 \mathrm{~min}$ with $0.3 \%$ hydrogen peroxide in methanol. After three washes with PBS, the sections were incubated with DBA-peroxidase (diluted $1: 10)$, WGA-peroxidase $(1: 20)$, or UEA-I-peroxidase $(1: 10)$ for $3 \mathrm{~h}$ at room temperature. Signals were developed using a diaminobenzidine (DAB) substrate kit (Vector Labs, USA). The sections were counterstained with hematoxylin before being mounted.

\section{Results}

\section{Histological analysis of the rat VNO}

The VNO is a paired, tubular-blind end organ in the ventral part of nasal septum. Analysis of cross-sections showed that VNO was encased by bony structure (Fig. 1A). The lumen of the VNO is lined by vomeronasal sensory epithelium at medial side (Fig. 1A, white arrow) and vomeronasal non-sensory epithelium at lateral side (Fig. 1A, arrow). In vomeronasal sensory epithelium, there are three types of cell layer; supporting cell layer, receptor cell layer and basal cell layer (Fig. 1B). At 4 weeks after birth, supporting cell layer (Fig. 1B, SC) had slender cell bodies and arranged at apical region. Receptor cell layer (Fig. 1B, RC), observed in the middle to the basal region of vomeronasal sensory epithelium, had a round nuclei. Unlike former two layers, basal cell layer was hard to identify clearly. Vomeronasal non-sensory epithelium located at lateral side of the lumen was consisted of pseudostratified 


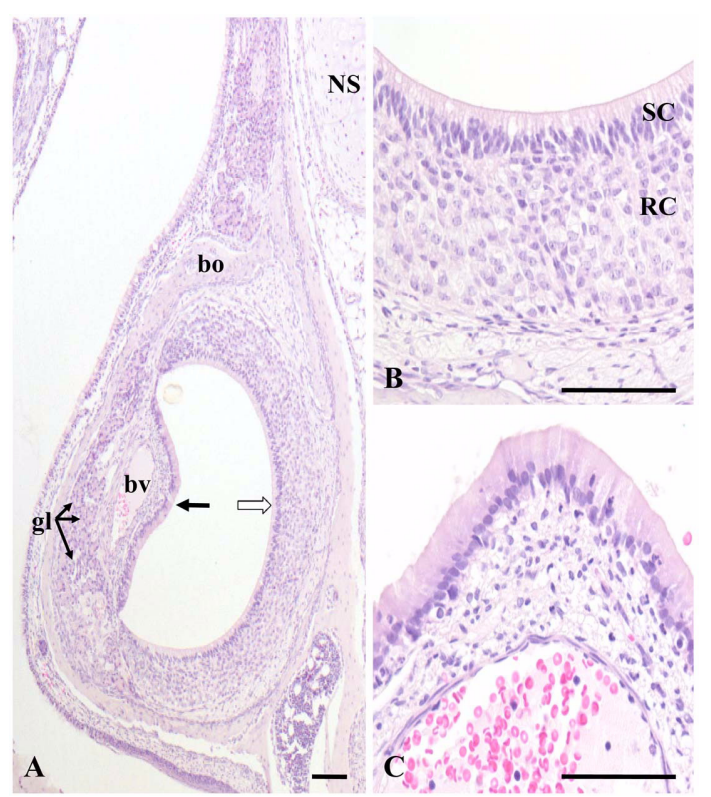

Fig. 1. Histological features of the rat vomeronasal organ (VNO) at 4 weeks old. Cross-section of the nasal septum stained by H\&E. (A) The rat VNO was encapsulated by bony structure. Two different type of epithelium, vomeronasal sensory epithelium (white arrow) and vomeronasal nonsensory epithelium (arrow), lined at each medial side and lateral side. In the lamina propria, there were a large blood vessel and numerous Jacobson's gland. (B) The higher magnification of vomeronasal sensory epithelium consisted of three cell layers; supporting cell layer, receptor cell layer and basal cell layer. (C) The higher magnification of nonsensory epithelium. bo: bony structure, gl: Jacobson's gland, bv: blood vessel, NS : nasal septum, SC: supporting cell, RC : receptor cell. Scale bars $=10 \mu \mathrm{m}$.

columnar epithelium (Fig. 1C). In the lamina propria (Fig. 1A), there were numerous acini of Jacobson's gland below vomeronasal non-sensory epithelium. A large blood vessel was seen between vomeronasal nonsensory epithelium and Jacobson's gland. At 1 day, 7 days and 8 weeks after birth, the morphological features of the rat VNO are similar to those at 4 weeks after birth except acini of Jacobson's gland.

\section{WGA}

One day after birth, the free border (Fig. 2A, arrowheads) of the vomeronasal sensory epithelium showed positive reactivity for WGA. Quite a few cells in the receptor cell layer were positive for WGA (Fig. 2A, arrows). However, other cell types, including supporting cells (Fig. 2A, white arrows), basal cells, were not positive for WGA. Vomeronasal non-sensory epithelium (Fig. 2B, arrowheads) showed weak positive reactivity for WGA. At this stage, acini of Jacobson's gland were not visible.

Seven days after birth, the free border (Fig. 2D, arrowheads) of the vomeronasal sensory epithelium showed intense reactivity for WGA. Certain receptor cells showed weak, diffuse reactivity for WGA (Fig. 2D, arrows). WGA was diffusely localized at the apical ends of supporting cells (Fig. 2D, white arrows); although, it was not easy to demarcate the cytoplasm of supporting cells from receptor cells at the apical region. WGA reactivity in the vomeronasal non-sensory epithelium (Fig. 2E, arrowheads) was weak. In the lamina propria, spot-like WGA reactivity was found on the luminal surface of the ductal epithelia (Fig. 2F, arrows). At this stage, acini of Jacobson's gland were not clearly visible.

Four weeks after birth, the free border (Fig. 2G, arrowheads) showed strong reactivity for WGA. Additionally, WGA was intensely localized to receptor cells, particularly in the apical half layer. Reactivity was concentrated at the apical region of receptor cell nuclei (Fig. 2G, arrows). Some supporting cells showed moderate reactivity for WGA (Fig. 2G, white arrows). In the vomeronasal non-sensory epithelium (Fig. 2H, arrowheads) showed moderate reactivity. WGA reactivity in the Jacobson's gland acini (Fig. 2I, arrows) was more intense than at 7 days after birth. Ductal epithelia (Fig. 2I, arrowheads) showed no WGA reactivity.

Eight weeks after birth, WGA was clearly detected in the cytoplasm of receptor cells in the apical half layer (Fig. 2J, arrows) and the supporting cells (Fig. 2J, white arrows). WGA reactivity in receptor cells was higher than at 4 weeks after birth (Fig. 2G, arrows). The free border showed intense WGA reactivity (Fig. 2J, arrowheads). Vomeronasal non-sensory epithelium (Fig. $2 \mathrm{~K}$, arrowheads) showed moderate reactivity at the apical region of epithelium. In the Jacobson's gland (Fig. 2L), WGA reactivity was of similar intensity to that at 4 weeks after birth. Acini (Fig. 2L, arrows) were positive for WGA, but not ductal epithelia (Fig. 2L, arrowheads).

\section{UEA-I}

One day after birth, the free border (Fig. 3A, arrowheads) of the vomeronasal sensory epithelium showed positive reactivity for UEA-I. Receptor cells (Fig 3B, arrows), supporting cells (Fig 3B, white arrows), and basal cells were negative for UEA-I. Apical 


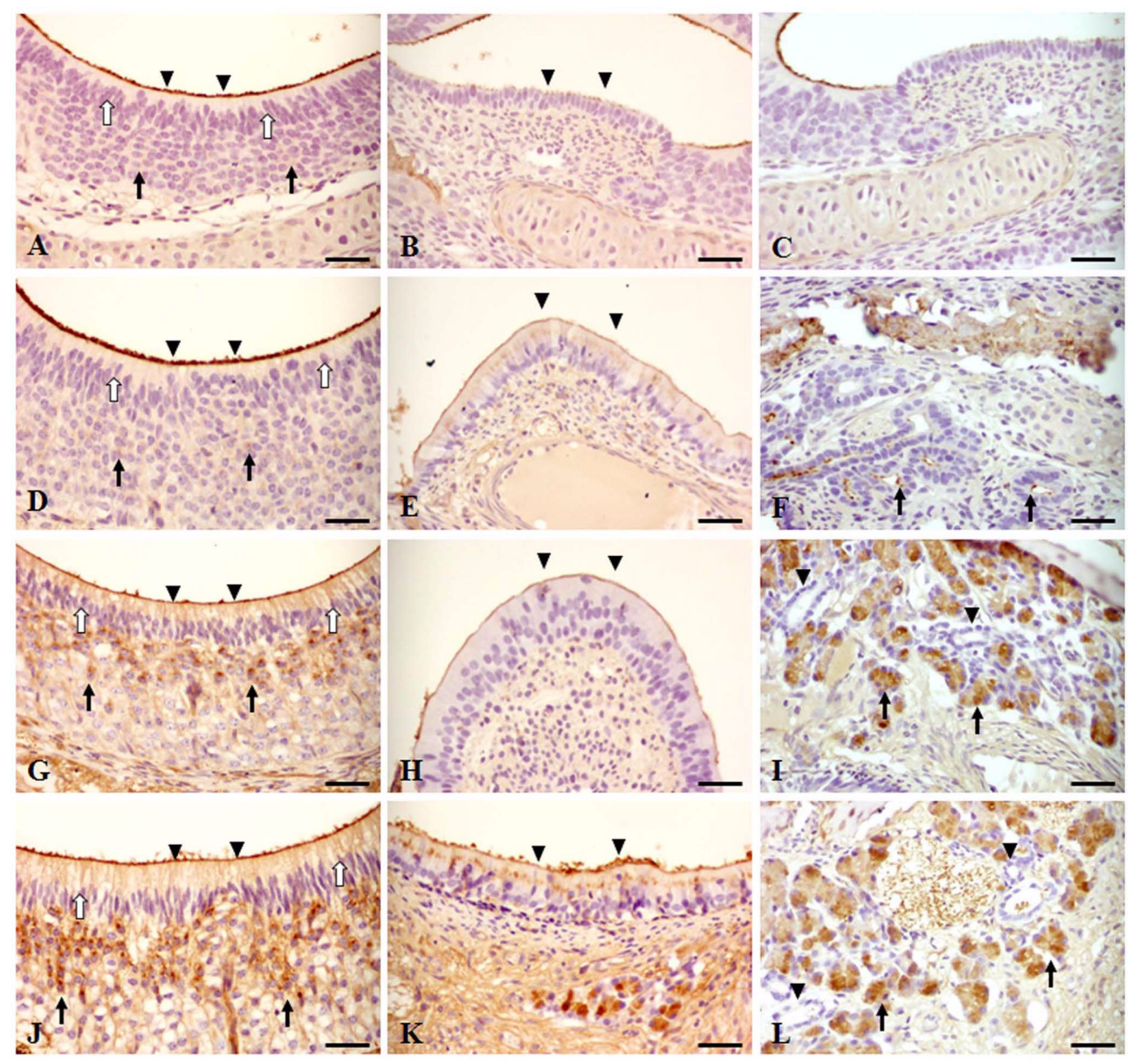

Fig. 2. Wheat germ agglutinin (WGA) histochemistry in the rat vomeronasal sensory epithelium (A, D, G, J), vomeronasal non-sensory epithelium $(\mathrm{B}, \mathrm{E}, \mathrm{H}, \mathrm{K})$ and lamina propria $(\mathrm{C}, \mathrm{F}, \mathrm{I}, \mathrm{L})$ at 1 day $(\mathrm{A}, \mathrm{B}, \mathrm{C}), 7$ days $(\mathrm{D}, \mathrm{E}, \mathrm{F}), 4$ weeks $(\mathrm{G}$, $\mathrm{H}, \mathrm{I})$, and 8 weeks after birth (J, K, L). Arrows (A, D, G, J) indicate receptor cells; arrowheads (A, D, G, J) indicate the free border, and white arrows (A, D, G, J) indicate supporting cells. Arrowheads (B, E, H, K) indicate the vomeronasal non-sensory epithelial cell. In the lamina propria, acini of Jacobson's gland (F) were not found at 7 days after birth, whereas ductal epithelia showed WGA reactivity (F, arrows). At 4 (I) and 8 (L) weeks after birth, acini (I, L, arrows), but not ductal epithelia (I, L, arrowheads), were positive for WGA. Scale bars $=25 \mu \mathrm{m}$.

region of vomeronasal non-sensory epithelium (Fig. 3B, arrowheads) showed weak reactivity. At this stage, acini of Jacobson's gland were not found.

Seven days after birth (Figs. 3D F), the free border (Fig. 3D, arrowheads) of the vomeronasal sensory epithelium showed intense reactivity for UEA-I. Some receptor cells (Fig. 3D, arrows) showed weak, diffuse reactivity for UEA-I, but not in the supporting cells (Fig. $3 \mathrm{D}$, white arrows). In the vomeronasal non-sensory epithelium (Fig. 3E, arrowheads) showed moderate reactivity. In the lamina propria, UEA-I reactivity was not found in the Jacobson's gland acini (Fig. 3F).

Four weeks after birth (Figs. 3G I), UEA-I was diffusely localized in receptor cells, with intense reactivity detected in the apical half layer (Fig. 3G, arrows). UEA-I reactivity was intense at the apical region of receptor cell nuclei. At this stage, UEA-I reactivity in the free border was less intense; although, the receptor cells showed intense reactivity. Some supporting cells (Fig. 3G, white arrows) showed positive reactivity for UEA-I. The vomeronasal non-sensory epithelium (Fig. 3H, arrowheads) showed moderate 


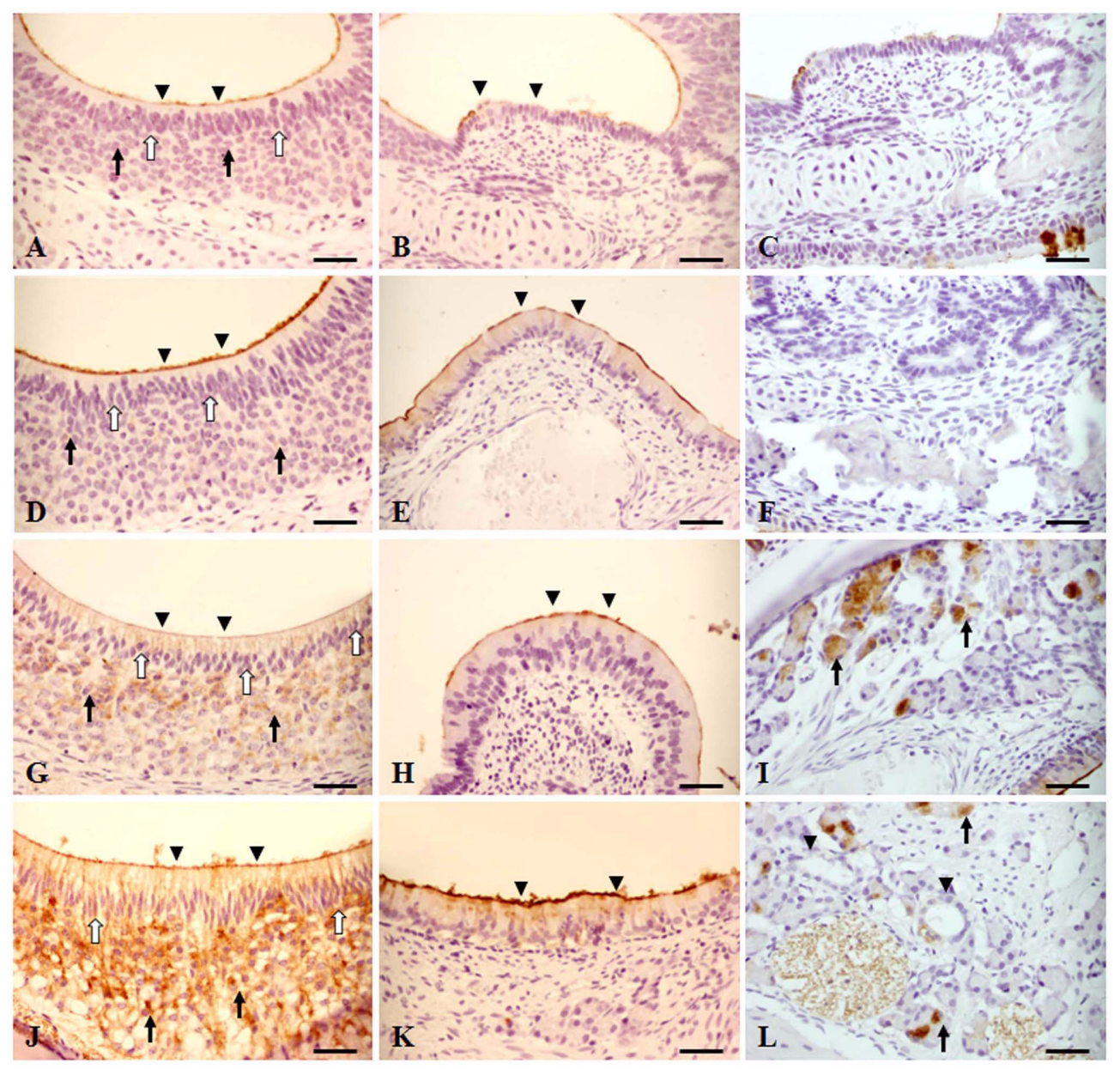

Fig. 3. Ulex europaeus agglutinin I (UEA-I) histochemistry in the rat vomeronasal sensory epithelium (A, D, G, J), vomeronasal non-sensory epithelium $(\mathrm{B}, \mathrm{E}, \mathrm{H}, \mathrm{K})$ and lamina propria $(\mathrm{C}, \mathrm{F}, \mathrm{I}, \mathrm{L})$ at 1 day $(\mathrm{A}, \mathrm{B}, \mathrm{C}), 7$ days $(\mathrm{D}, \mathrm{E}, \mathrm{F})$, 4 weeks $(\mathrm{G}, \mathrm{H}, \mathrm{I})$, and 8 weeks after birth $(\mathrm{J}, \mathrm{K}, \mathrm{L})$. Arrows $(\mathrm{A}, \mathrm{D}, \mathrm{G}, \mathrm{J})$ indicate receptor cells, arrowheads $(\mathrm{A}, \mathrm{D}, \mathrm{G}$, J) indicate the free border, and white arrows (A, D, G, J) indicate supporting cells. Arrowheads (B, E, H, K) indicate the vomeronasal non-sensory epitheilium. At 4 weeks after birth (I), UEA-I showed positive reactivity in some acini of Jacobson's glands (I, arrows). Eight weeks after birth (L), acini (L, arrows) but not ductal epithelia (L, arrowheads), were positive for UEA-I. Scale bars $=25 \mu \mathrm{m}$.

reactivity. In the lamina propria, positive UEA-I reactivity was found in some acini (Fig. 3I, arrows).

Eight weeks after birth (Figs. 3J L), the histochemical UEA-I pattern was similar to that at 4 weeks after birth, with increased intensity in all regions, including the free border (Fig. 3J, arrowheads), receptor cells (Fig. 3J, arrows), and supporting cells (Fig. 3J, white arrow). Vomeronasal non-sensory epithelium (Fig. 3B, arrowheads) showed moderate reactivity at the apical region of epithelium and weak positive reactivity at the basal part of epithelium. In the lamina propria, some acini (Fig.
3L, arrows), but not the ductal epithelia (Fig 3L, arrowheads), were positive for UEA-I.

\section{DBA}

One day after birth, the free border (Fig. 4A, arrowheads) showed moderate reactivity for DBA. In contrast, receptor cells (Fig. 4A, arrows) and supporting cells (Fig. 4A, white arrows) showed no DBA reactivity. Vomeronasal non-sensory epithelium (Fig. 4B, arrowheads) showed negative reactivity. At this stage, acini were not clearly visible. 


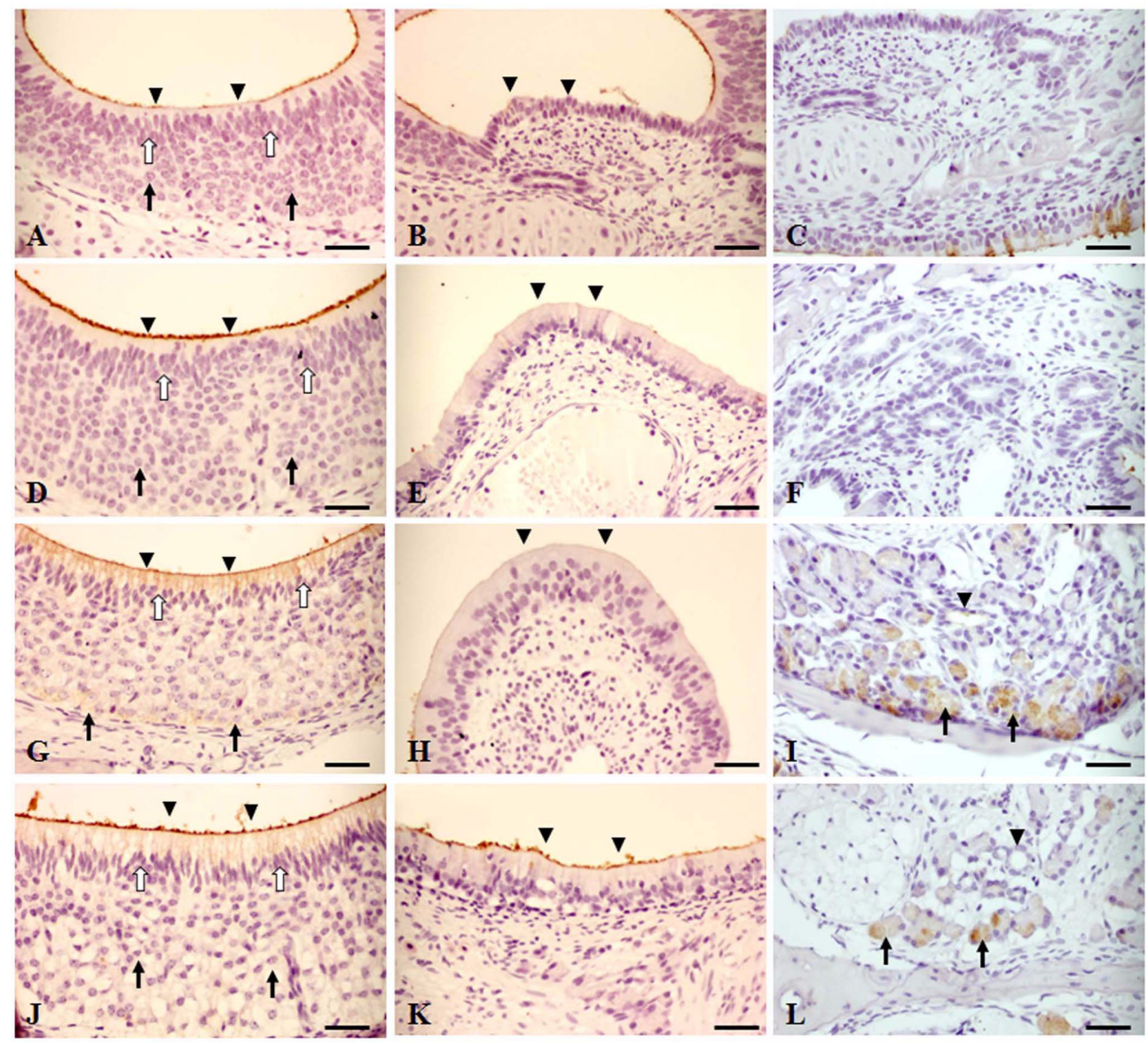

Fig. 4. Dolichos biflorus agglutinin (DBA) histochemistry in the rat vomeronasal sensory epithelium (A, D, G, J), vomeronasal non-sensory epithelium $(\mathrm{B}, \mathrm{E}, \mathrm{H}, \mathrm{K})$ and lamina propria $(\mathrm{C}, \mathrm{F}, \mathrm{I}, \mathrm{L})$ at 1 day $(\mathrm{A}, \mathrm{B}, \mathrm{C}), 7$ days $(\mathrm{D}, \mathrm{E}, \mathrm{F})$, 4 weeks $(\mathrm{G}, \mathrm{H}, \mathrm{I})$ and 8 weeks after birth $(\mathrm{J}, \mathrm{K}, \mathrm{L})$. Arrows (A, D, G, J) indicate receptor cells, arrowheads (A, D, G, J) indicate the free border, and white arrows (A, D, G, J) indicate supporting cells. Arrowheads (B, E, H, K) indicate the vomeronasal non-sensory epithelium. At 4 weeks (I) and 8 weeks (L) after birth, DBA reactivity was moderate in the Jacobson's gland acini (I, arrows) but weak (I, arrowhead) or absent (L, arrowhead) in the ductal epithelia. Scale bars = $25 \mu \mathrm{m}$.

Seven days after birth, the free border (Fig. 4D, arrowheads), but not the receptor cells (Fig. 4D, arrows) nor supporting cells (Fig. 4D, white arrows), of the vomeronasal sensory epithelium showed positive reactivity for DBA. Vomeronasal non-sensory epithelium (Fig. 4E, arrowheads) showed negative reactivity, but weak in the apical region of the epithelium. In the lamina propria, there is no DBA reactivity for the acini and the ductal epithelium of the Jacobson's gland (Fig. 4F).

Four weeks after birth, the free border (Fig. 4G, arrowheads) showed weak reactivity for DBA. Additionally, DBA was detected in supporting cells (Fig. $4 \mathrm{G}$, white arrows) at the apical region and in the some cells, possibly receptor cells (Fig. 4G, arrows) at the basal region. Vomeronasal non-sensory epithelium (Fig. $4 \mathrm{H}$, arrowheads) showed no reactivity. In the lamina propria, DBA reactivity was found in Jacobson gland acini (Fig. 4I, arrows), which did not show DBA reactivity at 4 weeks after birth. In the ductal epithelia (Fig. 4I, arrowhead), DBA reactivity was occasionally detected, as was the case at 7 days post birth.

Eight weeks after birth, DBA was histochemically detected in the free border (Fig. 4J, arrowheads) and supporting cells (Fig. 4J, white arrows). At this stage, DBA reactivity was not detected at the basal or apical ends of receptor cells (Fig. 4J, arrows). Apical region 
Table 1. Lectin binding in the vomeronasal sensory epithelium, vomeronasal non-sensory epithelium and Jacobson's glands of the rat

\begin{tabular}{|c|c|c|c|c|c|c|c|}
\hline \multirow{2}{*}{ Lectin type } & \multicolumn{4}{|c|}{ VSE } & \multirow[t]{2}{*}{ VNE } & \multirow[t]{2}{*}{ Gland acini } & \multirow[t]{2}{*}{ Age group } \\
\hline & Free border & Receptor cell & Supporting cell & Basal cell & & & \\
\hline \multirow[t]{4}{*}{ WGA } & $++^{\mathrm{a}}$ & + & - & - & + (weak) & - & P1D \\
\hline & ++ (intense) & + & - & - & + (weak) & + (weak) & P7D \\
\hline & ++ & ++ & + & - & + & ++ & P4W \\
\hline & ++ (intense) & ++ (intense) & + & - & ++ & ++ & P8W \\
\hline \multirow[t]{4}{*}{ UEA-I } & + & - & - & - & + (weak) & - & P1D \\
\hline & ++ (intense) & + & - & - & + & - & P7D \\
\hline & + (weak) & + & + (weak) & - & + & + & P4W \\
\hline & ++ & ++ & + & - & ++ & $+($ weak $)$ & P8W \\
\hline \multirow[t]{4}{*}{ DBA } & + & - & - & - & - & - & P1D \\
\hline & ++ & - & - & - & - & - & P7D \\
\hline & $+($ weak $)$ & - & + & - & - & ++ & P4W \\
\hline & ++ & ++ & + (weak) & - & + & + & P8W \\
\hline
\end{tabular}

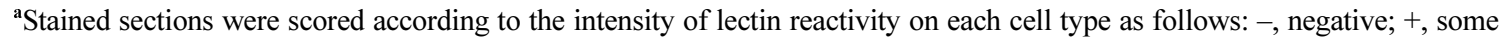
positive; ++, all positive. P1D, postnatal 1 day; P7D, postnatal 7 days; P4W, postnatal 4 weeks; P8W, postnatal 8 weeks; VSE, vomeronasal sensory epithelium; VNE, vomeronasal non-sensory epithelium.

of vomeronasal non-sensory epithelium (Fig. 4K, arrowheads) showed moderate reactivity. In the lamina propria (Fig. 4L), some acini (Fig. 4L, arrows), but not ductal epithelia (Fig 4L, arrowhead), were positive for DBA. The reactivity of three lectins, WGA, UEA-I and DBA, in the VNO of rats were summarized in Table 1.

\section{Discussion}

This is the first study of the binding patterns of three different lectins, WGA, UEA-I, and DBA, in the developing rat VNO. Previous studies have reported lectin binding patterns in the rat $\mathrm{VNO}$, but only in a single age group [1, 17, 18].

The present study found that WGA and UEA-I show similar binding patterns to each other in the rat VNO. Receptor cells, supporting cells, and some acini in the Jacobson gland were positive for WGA and UEA-I. Furthermore, our study revealed that two different types of receptor cells exist in the rat VNO: apical and basal receptor cells. In the present study, the reactivity for WGA and UEA-I was intense in the apical layer and moderate in the basal layer. In a previous study, 2 layers of receptor cells were also found in the mouse VNO [20].

DBA has also been previously detected in receptor cells in the mouse VNO [11], but not in rat receptor cells [18]. In the present study, we found that a number of receptor cells were positive for DBA in the rat VNO. This discrepancy may stem from differences in sensitivity and/ or in the source of the lectins. WGA and UEA-1 were showed moderate reactivity in vomeronasal non-sensory epithelium, but it showed weak reactivity in the DBA.

Lectin binding patterns in olfactory receptors in the olfactory epithelium, vomeronasal organ, and septal olfactory organ of Masera were previously studied in rats [17]. We have now shown, for the first time, that acini of Jacobson's gland are not fully developed at postnatal day 1, when few ducts were found. However, ducts were clearly visible in the Jacobson gland at day 7 after birth. Acini and ductal epithelia of Jacobson's gland were both clearly visible in the VNO at 4 weeks after birth. We have further shown that some gland acini in the VNO at 4 weeks after birth were positive for the lectins examined in this study. The source of lectins in the VNO free border at 1 day and 7 days after birth will require further study. As for lectin reactivity in ducts in the Jacobson's gland, we detected lectins in spot-like patterns in certain ductal epithelia at 7 days after birth, but not at 4 or 8 weeks after birth. Some acini of Jacobson's gland showed positive lectin reactivity. The transient lectin reactivity in some ducts in the VNO should be further studied. With regard to lectin reactivity in the Jacobson's gland, we postulate that some fully developed acini at 4 weeks after birth were positive for the lectins examined in this study, and that ductal epithelia in the Jacobson's gland are transiently positive 
for lectins, including WGA, UEA-I and DBA, at a certain stage around 7 days after birth.

\section{References}

1. Barber PC. Ulex europeus agglutinin I binds exclusively to primary olfactory neurons in the rat nervous system. Neuroscience 1989, 30, 1-9.

2. Bartoshuk LM, Beauchamp GK. Chemical senses. Annu Rev Psychol 1994, 45, 419-449.

3. Bigiani A, Mucignat-Caretta C, Montani G, Tirindelli R. Pheromone reception in mammals. Rev Physiol Biochem Pharmacol 2005, 154, 1-35.

4. Brennan PA. The vomeronasal system. Cell Mol Life Sci 2001, 58, 546-555.

5. Dam TK, Brewer CF. Lectins as pattern recognition molecules: the effects of epitope density in innate immunity. Glycobiology 2010, 20, 270-279.

6. Garrosa M, Gayoso MJ, Esteban FJ. Prenatal development of the mammalian vomeronasal organ. Microsc Res Tech 1998, 41, 456-470.

7. Ichikawa M, Shin T, Kang MS. Fine structure of the vomeronasal sensory epithelium of Korean goats (Capra hircus). J Reprod Dev 1999, 45, 81-89.

8. Jia C, Halpern M. Calbindin D28K immunoreactive neurons in vomeronasal organ and their projections to the accessory olfactory bulb in the rat. Brain Res 2003, 977, 261-269.

9. Kieda C. Role of lectin-glycoconjugate recognitions in cell-cell interactions leading to tissue invasion. Adv Exp Med Biol 1998, 435, 75-82.

10. Lee JY, Kang TY, Lee YD, Shin TK. Histochemical characterization of the lectin-binding sites in the equine vomeronasal organ. J Vet Sci 2003, 4, 15-19.

11. Lundh B, Brockstedt U, Kristensson K. Lectinbinding pattern of neuroepithelial and respiratory epithelial cells in the mouse nasal cavity. Histochem $\mathbf{J}$ 1989, 21, 33-43.

12. Mendoza AS, Kuhnel W. Lectin histochemistry on the olfactory region and the vomeronasal organ or rats and golden hamsters. Acta Histochem 1991, 91, 173-184.

13. Morse A. Formic acid-sodium citrate decalcification and butyl alcohol dehydration of teeth and bones for sectioning in paraffin. J Dent Res 1945, 24, 143-153.

14. Nakajima T, Shiratori K, Ogawa K, Tanioka Y,
Taniguchi K. Lectin-binding patterns in the olfactory epithelium and vomeronasal organ of the common marmoset. J Vet Med Sci 1998, 60, 1005-1011.

15. Oikawa T, Saito H, Taniguchi K. Immunohistochemical studies on the differential maturation of three types of olfactory organs in the rats. J Vet Med Sci 2001, 63, 759-765.

16. Park J, Lee W, Jeong C, Kim H, Taniguchi K, Shin T. Developmental changes affecting lectin binding in the vomeronasal organ of domestic pigs, Sus scrofa. Acta Histochem 2012, 114, 24-30.

17. Saito H, Ogawa K, Taniguchi K. Lectin-binding patterns of the olfactory receptors (olfactory epithelium, vomeronasal organ and septal olfactory organ of Masera) in the rat. Jikken Dobutsu 1994, 43, 51-60.

18. Salazar I, Sánchez Quinteiro P. Lectin binding patterns in the vomeronasal organ and accessory olfactory bulb of the rat. Anat Embryol (Berl) 1998, 198, 331-339.

19. Salazar I, Sanchez-Quinteiro P, Lombardero M, Cifuentes JM. A descriptive and comparative lectin histochemical study of the vomeronasal system in pigs and sheep. J Anat 2000, 196, 15-22.

20. Salazar I, Sanchez Quinteiro P. Differential development of binding sites for four lectins in the vomeronasal system of juvenile mouse: from the sensory transduction site to the first relay stage. Brain Res 2003, 979, 15-26.

21. Takami S, Getchell ML, Getchell TV. Lectin histochemical localization of galactose, N-acetylgalactosamine, and $\mathrm{N}$-acetylglucosamine in glycoconjugates of the rat vomeronasal organ, with comparison to the olfactory and septal mucosae. Cell Tissue Res 1994, 277, 211-230.

22. Taniguchi K, Saito S. Phylogenic outline of the olfactory system in vertebrates. J Vet Med Sci 2011, 73, 139-147.

23. Taniguchi K. Embryonic and postnatal differentiation of olfactory epithelium and vomeronasal organ in the Syrian hamster. J Vet Med Sci 2008, 70, 57-64.

24. Tirindelli R, Dibattista M, Pifferi S, Menini A. From pheromones to behavior. Physiol Rev 2009, 89, 921-956.

25. Wu AM. Carbohydrate structural units in glycosphingolipids as receptors for Gal and GalNAc reactive lectins. Neurochem Res 2002, 27, 593-600. 